Review

\title{
Biology, properties and clinical application of Mesenchymal stem cells
}

\author{
Peyman Ghoraishizadeh ${ }^{1}$, Shraddha Raikar ${ }^{2}$, Afsoon Ghorishizadeh ${ }^{3}$, Mohadese Hashem Boroojerdi ${ }^{4}$, \\ Nasibeh Daneshvar ${ }^{4}$ \\ ${ }^{1}$ Universidad de Los Andes, Santiago, Chile \\ ${ }^{2}$ Manipal School of Regenerative Medicine, Manipal University, Bangalore, India \\ ${ }^{3}$ Islamic Azad University of Ahar, Ahar, Iran \\ ${ }^{4}$ Universiti Putra Malaysia, Serdang, Selangor, Malaysia
}

Received 23 January 2014, Revised 11 April 2014, Accepted 23 April 2014

(C) 2014, Ghoraishizadeh P., Raikar S., Ghorishizadeh A., Boroojerdi M.H., Daneshvar N.

(C) 2014, Russian Open Medical Journal

Abstract: Stem cells are originally divided into two major categories of embryonic stem cells and adult stem cells. Mesenchymal stem cells (MSCs) are of the most important adult stem cells which have attracted the attention of most researchers. MSCs are plastic adherent, spindle shaped cells with mutipotent potency which able to differentiate into osteoblastic, chondrogenic, adipogenic lineages, while recent studies have demonstrated that MSCs are also able to differentiate into other lineages, like neuronal and cardiomyo-genic lineage. They participate in repairing tissues such as bone, cartilage, muscle, tendon and fat. Potency of MSCs along with immunosuppressive properties have make them proper candidate for stem cell based therapy trails. In this study, biology and properties of MScs is described at the end recent clinical application of these cells will be discussed.

Keywords: mesenchymal stem cells, multipotent, immunosuppressive, cell therapy

Cite as Ghoraishizadeh P, Raikar S, Ghorishizadeh A, Boroojerdi MH, Daneshvar N. Biology, properties and clinical application of Mesenchymal stem cells. Russian Open Medical Journal 2014; 3: 0202.

Correspondence to Nasibeh Daneshvar. Address: Institute of Bioscience, Universiti Putra Malaysia, 43400 Serdang, Selangor, Malaysia.

E-mail: Daneshvar.n64@gmail.com

\section{Biology of mesenchymal stem cells}

Stem cells are originally divided into two major categories of embryonic stem cells and adult stem cells. Mesenchymal stem cells are of the most important adult stem cells which have attracted the attention of most researchers. Mesenchymal stem cells participate in repairing tissues such as bone, cartilage, muscle, tendon and fat. Of course, these cells are considered as supporting cells for hematopoietic cells in bone marrow as well. These cells were obtained for the first time by Friedenstein and Petrakova from rat bone marrow. Bone marrow is the most accessible source which is suggested to use these cells. Although these cells can be isolated from other resources such as liver, blood cell from neonatal (infants), umbilical cord blood, and amniotic fluid, these cells constitute 0.001 to 0.1 percent of population of nucleated human bone marrow cells and are isolated from Iliac Crest [1] and have the capability of being isolated from Femur [2]. It is interesting to know that these cells have capability of being proliferated and increased in the laboratory medium (in-vitro) excellently. Mesenchymal stem cells, which have been recognized as underlying bone marrow and/or mesenchymal progenitor cells, are considered as cells with high proliferation capability and have the potential to differentiate into several types of cells. These cells are called as adult stem cells. In different studies, these cells have been applied with different names. As a matter of fact, all these cells are duly called as mesenchymal stem cells [2] (Table 1).
Table 1. Examples of various names which have been given to these cells in various studies

\begin{tabular}{l}
\multicolumn{1}{c}{ Definition } \\
$\begin{array}{l}\text { Bone marrow adhesion cells: including } \\
\text { fibroblast-quasi cells, endothelial cells and }\end{array}$ \\
monocyte and macrophages cells. \\
Colonies of fibroblast cells in the presence \\
of monocyte and macrophages cells
\end{tabular}


Isolation is conducted based on adhesive property of mesenchymal stem cells (MSCs) to the culture dishes, despite lack of adhesion of hematopoietic cells. In fact, this isolation method has thus far been identified and used as standard method for isolating mesenchymal stem cells (MSCs) [3].

Isolating, identifying and studying specifications of these cells have been carried out excellently in a number of vertebrates such as human, rat, dog, rabbit, sheep, chicken and pig, horse and cow. Colonies of mesenchymal cells are considered as non-uniformity colonies which probably include osteoblast cells and progenitor bone cells, fat cells (adipocytes), fibroblasts, reticular cells, macrophages, endothelial cells and even a partial of blood cells and hematopoietic stem cells as well. So, if these cells, stuck to the dish, showed capability to differentiate into cartilage and bone cells in the laboratory medium, they will be identified as mesenchymal stem cells (MSCs) [4].

As a matter of fact, human mesenchymal stem cells (MSCs) are of the cells which should meet the following three criteria according to the definition of International Society for Cellular therapy (ISCT).

In normal culture conditions, MSCs should stick to the bottom of container in plastic culture dishes.

MSCs should explain surface CD90, CD73 and CD105 markers and should be negative in explaining hematopoietic indicators particularly CD45, CD34 and other indicators such as CD14 or CD11b, CD79 alpha or CD19 and HLA-DR.

MSCs should be able to differentiate into fat, cartilage and bone cells in vitro conditions [5].

Mesenchymal cells are culture and developed in cultured mediums containing bovine or human serum. During various passages, these cells reach one homogenous population in terms of adherence to the dish morphologically.

\section{Niche of mesenchymal stem cells}

Niche of a cell is microenvironment factors which engulf the cell; niche is called as a multidimensional volume cloud which surrounds the cell. They are important for maintenance and quiescence and regulate cellular survival and proliferation [6] to know which factor constitute niche of the mesenchymal cells is a discussion which make research in this field more attractiveness. Of course, it is obvious that there is a certain niche in the bone marrow which provides survival of hematopoietic cells through releasing numerous factors and establishing adhesiveness conditions for them. It seems that this niche may be constituted from bone progenitor cells [6].

Stroma and stromal cells provide a physical place for the maturity of blood cells. Stromal and stromal cells have a wide spectrum of secretions and signals from different cells which are required for differentiating and maturation of hematopoietic cells [7].

Endothelial cells, fat cells, macrophages, reticular cells, fibroblasts and bone progenitor cells, hematopoietic cells are the cells derived from stromal and stromal cells which constitute physical space of bone marrow [8].

In fact, it is the space which is assumed in the bone marrow for mesenchymal cells. Here, the following question is posed: the very mesenchymal cells are affected by the same niche which is made for hematopoietic cells. Of course, it can be assumed that these two cell groups (mesenchymal and hematopoietic cells) make a special niche with the cooperation and interaction of each other. It should be noted that intracellular and extracellular signals differ from one another completely which receive during their development. So, better identification of this niche provides better culture conditions and also better development of mesenchymal cells in the laboratory medium. Mesenchymal cells can be accessed and are available from various resources other than bone marrow such as Trabecular bones, fat and liver tissues, synovium, skeletal muscles, lungs and milky teeth [9] Warton's Jelly and umbilical cord and Placenta [10], niche will not be considered as mesenchymal cells merely to the bone marrow and experiences different niches in various tissues. Perhaps, mesenchymal cells may experience identical and equal niches in various parts of the body. Over all understanding of niche's mechanism in self-renewal maintenance will lead to better understanding of stem cell behavior because these mechanisms are key to regulate of homeostasis and contribute to aging and tumorigenesis when altered during adulthood $[11,12]$.

\section{Differentiated potential of mesenchymal stem cells}

Up to the present time, differentiation of these cells has been shown to the various cells such as osteoblast, chondrocyte, adipocyte, endothelial cells, neural cells, cardiomyocyte cells, hepatocyte cells and pancreatic cells $[3,4,13-20]$ in various types of mammals. So, the terms "Multipotent" and "Pluripotent" are used reciprocally for these cells. As a matter of fact, differentiation is the process, in which, one stem cell shows the ability of being turned into other cellular categories.

The recent studies in cellular transplantations have shown that, mesenchymal stem cells which are able to become the cells derived from mesoderm category, can be turned into the cells with the specifications of ectoderm and endoderm cells in laboratory environment. The said issue indicates existence of phenomenon of conversion and differentiation in mammals cells category. Although some researcher believe that results of these studies can be result of presence of progenitor cells or even cellular attached phenomenon, the studies have shown that these mesenchymal stem cells have been committed to create a series of cell With creating motivations and artificial messages, these cells have the ability of turning into the other cellular categories.

In a study, the potential of differentiation of bone cells, originated from human bone marrow mesenchymal cells to fat and cartilage cells, has been examined. it was observed that mesenchymal cells, which are cultured under specific conditions of being turned into the bone cells, maintain the ability of turning into the fat and bone cells maximum within 30 days so Understanding how pathways mediating the trans-differentiation between osteoblasts and adipocytes are regulated should be of relevance to the development of therapeutic control of bone loss in osteoporosis [21].

In a study made in mesenchymal stem cells isolated from rat bone marrow, mesenchymal stem cells were first converted into the neural stem cell, with the ability of formation of neuro-sphere, in the laboratory medium under different treatments. Then, created stem cells showed the ability of formation of neurons in the laboratory medium. The mesenchymal cells have capability of being differentiated into the endodermic cells as well. Different studies have been conducted with regard to differentiate bone marrow stem cells of mouse and rat into hepatocyte in the culture environment. But for more interpretation and approval, we always need to study differentiation and activity of cells in the body of living organism. Growth factors and different differentiation have 
been used in different studies to differentiate bone marrow stem cells into the cells indicating gene and albumin protein and hepatocyte-quasi cells, the most important of which can be referred to hepatocyte growth factor, fibroblast growth factor and epidermal growth factor. It is shown that hepatocyte growth factor can cause differentiation of mouse bone marrow stem cells into the hepaticyte-quasi cells which express albumin [22, 23].

In other studies, differentiation of human bone marrow stem cells has been shown in various conditions, using growth factors $[24,25]$ and or co-culture [26] and also mesenchymal stem cells derived from human fat tissue [27] towards liver cells.

Mesenchymal stem cells showed the ability to differentiate into mesoderm cells in laboratory culture conditions, Makino, et al. showed the differentiation of mesenchymal cells towards cardiomyocyte cells in the laboratory environment, influenced by 5-Azacytidine matter, for the first time. They created cardiomyogeneics cells category from mouse mesenchymal cells [28].

Other studies showed the ability of differentiation of mesenchymal cells in co-culture conditions with rat cardiomyocyte cells $[29,30]$.

In a different study, since using 5-Azacytidine matter cannot be considered as a proper option in subsequent approaches, differentiation of human mesenchymal cells to the cardiomyocyte cells studied in different conditions and in the vicinity of mixture of growth factors and hormones [31].

The laboratory studies on the potential of differentiation of human mesenchymal stem cells towards cardiomyocyte cells include the studies that have merely studied the influence of 5Azacytidine matter on the mesenchymal stem cells [28] or have reported the impact of mixture of various factors [31,32] or have reported the co-culture impact of neonatal cardiomyocytes or even cardiomyocyte cellular categories $[21,30,33]$ or co-culture with adult cardiomyocyte cells [34, 35].

Although molecular and cellular mechanisms of differentiation of mesenchymal cells have not been identified correctly, it seems that commitment of mesenchymal cells to the bone and cartilage cells or fat cells need stating Cbfa-1 and Peroxisome ProliferatorActivated Receptors (PPARy2) molecules respectively and increase towards bone cells, such as alkaline phosphates, osteopontin, osteocalcin and collagen type I, in final differentiation while the increasing rate in molecules of collagen type II and IX causes differentiation to the cartilage cells and in differentiation of mesenchymal cells towards fat cells (adipocytes), the rate of molecules aP2, Adipsin 4, Leptin and lipoprotein lipase is increased [36].

In a study conducted by Shiota et al., mesenchymal cells have been cultured after being separated from bone marrow and isolated from hematopoietic cells in the laboratory and after the first culture in adhesive state, their mesenchymal cells have been cultured in non-adhesive conditions in order to form sphere-like structures called "sphere". Under such circumstances, necetin indicator is stated clearly and finally, these spheres are crushed in order to create single cells. These spheres were cultured in adhesive condition and observed that mesenchymal cells showed markers of neural cells, muscular cells and heart beating cells [37].

\section{Immune escape of mesenchymal stem cells}

Various studies have shown that mesenchymal cells do not create noticeable immune response in allogeneic lymphocytes.
The mechanism of this phenomenon, i.e. how this phenomenon is occurred, has not been fully identified. However, mesenchymal stem cells, lacking MHC class II, have been identified and approved properly [38]. Of course, Le Blanc showed that these cells state MHC molecule class II as intercellular bases and if it is inducted with cytokine IFN gamma, it will update on its surface. It is interesting to know that the cells, which have faced with IFN gamma, they do not create immune response in allogeneic lymphocytes like other MHC cells (positive class I) and (negative class II). This issue shows the important and basic role of IFN (interferon) gamma in the inhibition of MSCs-mediated immune response [39].

The studies consistent with this finding have shown that adding antibody against interferon gamma receptor to the culture medium prevent inhibition of immune response by the mesenchymal cells on $\mathrm{T}, \mathrm{CD} 4+$ and $\mathrm{CD} 8+$ cells and even natural killer cells [40] (Figure 1).

Even, another study has shown that cells expressing MHC class II are not able to stimulate the immune system.

Culturing $\mathrm{T}$ cells with mesenchymals although increases expression of MHC class II molecules on surface of these cells with the secretion of interferon gamma, they will not be able to create immune response due to the lack of auxiliary molecules on surface of these cells. These data show that inaccessibility to mesenchymal stem cells and lack of their identification by the immune cells depends on a factor other than MHC.

Lack of emergence of immune response by $T$ cells against mesenchymal cells does not depend on expression of auxiliary molecules (B7-2) CD86 \& (B7-1) CD80 as well, for, transfer of these molecules to the mesenchymal cells does not affect induction of immune response. So, this property of non-irritability of allogenic immune system by mesenchymal cells has developed their usage in comparison with the autologous cells in the cell therapy. Of course, Eliopolous, et al. presented controversial article on using mesenchymal cells in allograft transplantations. When mesenchymal cells are cultured with lymphocytes in the presence of CD28 stimulating antibody, proliferation of $T$ cells are not observed and this issue has been well proven in autologous transplantation of MSCs in baboons, causing creation of immunological tolerance. Even, mesenchymal cells are not eradicated by the natural killer cells which indicate escape of mesenchymal cells from being identified by these killer cells [41].

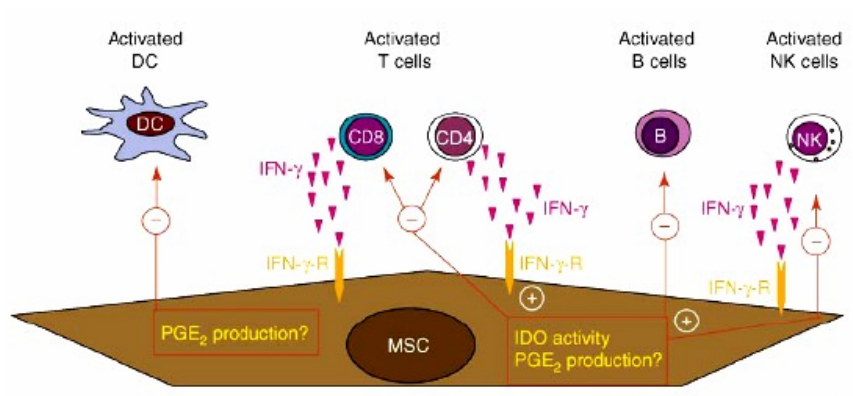

Figure 1. Role of interferon gamma in immune suppression. Activated T cells secrete interferon gamma which functions their inhibiting activity with connecting to its receptor on surface of mesenchymal cells on the other hand. Activated B cells are not affected normally from mesenchymal cells. Natural killer cells activate this route using spontaneous production of gamma interferon while activated DCs are exposed to the inhibitory effect of mesenchymal using prostaglandin pathway (E2) and perhaps other unknown pathways [40]. 
The rats, which have induced with mesenchymal cells expressing erythropoietin and incompatible hormone in terms of MHC, did not show any enhanced increase in hematocrit.

The rate of active immune cells, such as natural killer cells, CD8+ $T$ cells, and cytotoxic $T$ cells, has been increased in the samples receiving mesenchymal cells in comparison with the control group [41].

In another study, differentiated mesenchymal cells to the bone cells were grafted to a different rabbit in terms of $\mathrm{MHC}$ molecule and showed that these differentiated cells do not stimulate immune system despite presence of Class II MHC molecule. It should be noted that these data are consistent with the laboratory studies which have proven non-immunogenic of mesenchymal cells. The rate of expression of MHC antigens in mesenchymal cells can create a tolerance to the immune response to the mesenchymal stem cells. It seems that even mesenchymal cells, which lack Class $1 \mathrm{MHC}$ antigen, are not able to stimulate immune system and then, they are not considered as immunogenic. Although likely responses of natural killer cells with mesenchymal cells affect stability of autologous or allogeneic cells, they are dependent highly on expressing HLA-I on surface of underlying cells. The activity of natural killer cells is set through excitatory and inhibitory receptors and signals. For example, it can be referred to the activating or stimulating receptors such as NKp30, NKp44, and NKp46 which their ligands are unknown as well as lectin-like receptor of DNAM-1 and (NKG2D) C.

Killer Immunoglobulin-like receptors (KIRs) are the main inhibit receptors on the surface of killer cells which show reaction with allotype HLA antigen. Existence of class 1 molecules on the friendly cells leads to the occupation of positions of KIRs receptors, so, it inhibits the activity of natural killer cells. But cancerous cells and cells infected with virus are not able to activate KIRs receptors due to the decreased expression of Class $1 \mathrm{MHC}$ molecules. Therefore, they cannot cope with confront with cytotoxic activity of natural killer cells [42].

Spaggiari et al. showed that lysis is observed in autologous and allogeneic grafts of these cells with the mediation of natural killer cells. They showed that mesenchymal cells express ligands such as ULBP3, Nectin-2 and PVR, each of which are identified with different stimulating receptors by natural killer cells.

Moreover, blocking receptors with monoclonal antibodies show the involvement of receptors such as NKp30, NKG2D and DNAM-1 except NKp44. It is amazing to know that inhibiting Class 1 HLA antigens does not increase activity of lytic which is due to the less and mid presence of these molecules on the surface of mesenchymal cells [43].

\section{Transplanting Mesenchymal Stem Cell with Treatment Aim}

One of the most important applications of mesenchymal stem cells is to treat diseases. Of course, low and very low amount of these cells in resources such as bone marrow is one of the important problems of using mesenchymal stem cell. So, culturing and developing them in vitro (laboratory medium) and enhancing number of these cells are one of the major concerns of experts with regard to mesenchymal cells. As a matter of fact, using bioreactors, which provide culture of these cells to a great number, has been suggested to develop mesenchymal stem cells in the laboratory medium, so that number of these cells has been increased in vitro conditions during 8 days up to 29 fold more than that of its initial rate.
Since these cells are required in high number in most clinical cases, using bioreactors can be considered as one of the best strategies for their development [44].

Although most attentions of mesenchymal cells transplantation have been concentrated on Graft Versus Host disease (GVHD), the use of allogeneic mesenchymal stem cells has been reported in treatment of diseases treated through grafting body organ such as Hurler's Syndrome (mycopoly sacharidozir of IH type) and Metachromatic Leukodystrophy (MLD) as well. These injections are immune and initial observations have shown improvements in these patients [5].

Other studies, made by Horwitz, et al. have shown the positive role of mesenchymal cells in treatment of patients with Osteogenesis Imperfecta which is a type of genetic disease in collagen Type 1 [45].

First phase clinical study has been designed and conducted to use mesenchymal stem cells on 15 patients to study efficiency, isolation and proliferation of these cells in vitro and their transfer through vessel. The patients in three five-member groups received 1,10 and 50 million mesenchymal stem cells respectively and any reaction and implication was not observed among these patients. These injected cells are seen through vessel for a period in blood circulation. Of course, Koc et al. traced mesenchymal stem cells in the early hours after injection [46].

After injection, these cells adopt certain places in different tissues. The potential of remaining mesenchymal stem cells in bone, in intravenous transplantation of these cells, have been shown in infant with Osteogenic Imperfecta and one patient with aplastic anemia.

Following allogeneic transplantation of stem cells has been shown that all cells of the hematopoietic system and immune cells represent the source. Chemotherapy with high dose before autologous transplantation or allogeneic mesenchymal stem cells has caused destruction of bone marrow stromal tissue and has reduced its restoration process. This stromal destruction can create interference in retention of blooding after transplantation which reconstruction of stromal, using transplanted mesenchymal stem cells, may prevent this activity.

In the first study conducted to find whether mesenchymal stem cells increase or decrease retention of transplantation in autologous transplantations of stem cells, mesenchymal stem cells were isolated and cultured from patients with breast cancer who were supposed to receive cell through injection. For this purpose, 28 patients received 1 to 2 million mesenchymal stem cells through vessel and no toxicity was observed and blood-making improvement was accelerated. The results of this immune study have paved suitable way for further studies.

Mesenchymal stem cells express high levels of aryl sulfatase Idoronidasae, in which, defect in first molecule caused MLD while defect in the second molecule caused Hurler's disease. The mesenchymal isolated from donor was injected through vessel to the patients with MLD and Hurler's disease which has received cell previously. This injection showed the signs apparent improvement in nerve conduction velocity among four patients out of 5 with MLD. In another study, a 20-year-old female with chronic myeloid leukemia received mesenchymal stem cells, derived from her father's blood which was identical in terms of Haplotype (HLA) and this patient received transplantation very rapidly. Moreover, this patient did not show even acute and chronic GVHD. Her general conditions became well up to 31 months after transplantation and did not face any problem in this respect. Of course, it should be 
noted that this patient was a remarkable and unique sample with acceptable results that has been reported. It is interesting to know that using identical transplantation in terms of hallotype, which $T$ cells has not been removed from them; the danger of symptoms of GVHD and even rejection of graft is very high. In a study, eyecatching and stunning results were observed in a male patient who received GVHD Grade 4 against intestine and liver after transplantation of allogeneic stem cells taken from a female patient who was consistent in terms of HLA, A, B, and DR [47].

The studies, conducted on the effect of mesenchymal stem cells in Experimental Autoimmune Encephalomyelitis (EAE) of Multiple Sclerosis (MS) disease, showed that in this EAE model, peripheral lymphoid organs of this disease is adjusted through injection of mesenchymal stem cells with induction of toleration of T cells [48].

Further studies in this field showed that intravenous injection of mesenchymal stem cells in this model inhibits response of pathogenic B cells [49].

As a matter of fact, MS disease and its EAE model is indentified with removal of myelin membrane of nerve cells by activated immune cells, i.e. $T$ and $B$ cells, macrophages, and secretion of mesenchymal cells.

Mesenchymal stem cells prevent these injuries using two ways: 1) with inhibition of immune cells, 2) with the positive impact which exerts on neurons and astrocytes cells in terms of Trophic. These two ways play a leading role in inhibition of this disease [42] (Figure 2).

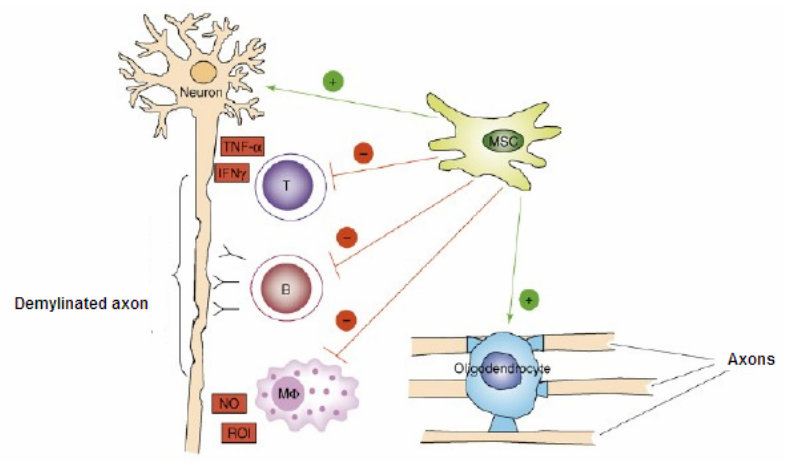

Figure 2. Way of dual function of mesenchymal stem cells (MSCs) in treatment of diseases. The different immune mechanisms, including $B$ and $T$ cells and macrophages, are involved in this phenomenon. Here, antibodies, cytokines secreted from macrophages, etc. are involved in this process. Injection of mesenchymal stem cells improves Experimental Autoimmune Encephalomyelitis (EAE). As shown in this figure, moreover placing severe inhibitory effect (red lines in the picture) on performance of $T$, B cells and macrophages, mesenchymal stem cells have trophic effect on nervous neurons and Oligodendrocyte (green lines) [42]

\section{Conclusion}

Immunosuppression activities and multipotent properties of MSCs have make them a proper candidate for cell therapy, but application of them in clinical therapy have been faced with serious problems due to the less engraftment and limited homing capacity of MSCs along with heterogeneity and dire need to the xenogeneic complement factors like FBS for proliferation of these cells. The strategies and researches are done in this regard in order to manipulate of MSCs and create optimal conditions to use these cells with the omission of serum from their culture medium and proliferation in great number using genetic engineering technology, bioreactors and looking for other accessible resources for isolation of MSCs.

Conflict of interest: none declared.

\section{References}

1. Friedenstein AJ, Piatetzky-Shapiro II, Petrakova KV. Osteogenesis in transplants of bone marrow cells. J Embryol Exp Morphol 1966; 16(3): 381-390. (PMID: 5336210).

2. Baksh D, Song L, Tuan RS. Adult mesenchymal stem cells: characterization, differentiation, and application in cell and gene therapy. Journal of cellular and molecular medicine 2004; 8(3): 301316. (PMID: 15491506) (doi: 10.1111/j.1582-4934.2004.tb00320.x)

3. Kemp KC, Hows J, Donaldson C. Bone marrow-derived mesenchymal stem cells. Leukemia \& lymphoma 2005; 46(11): 1531-1544. (doi: 10.1080/10428190500215076)

4. Alhadlaq A, Elisseeff JH, Hong L, Williams CG, Caplan Al, Sharma B, et al. Adult stem cell driven genesis of human-shaped articular condyle. Annals of Biomedical Engineering 2004; 32(7): 911-923. (PMID: 15298429).

5. Keating A. Mesenchymal stromal cells. Current Opinion in Hematology 2006; 13(6): 419-425. (doi: 10.1097/01.moh.0000245697.54887.6f)

6. Calvi LM, Adams GB, Weibrecht KW, Weber JM, Olson DP, Knight MC, et al. Osteoblastic cells regulate the haematopoietic stem cell niche. Nature 2003; 425(6960): 841-846 (doi: 10.1038/nature02040)

7. Tavassoli M, Takahashi K. Morphological studies on long-term culture of marrow cells: characterization of the adherent stromal cells and their interactions in maintaining the proliferation of hemopoietic stem cells. The American Journal of Anatomy 1982; 164(2): 91-111 (doi: 10.1002/aja.1001640202).

8. Wang QR, Yan ZJ, Wolf NS. Dissecting the hematopoietic microenvironment. VI. The effects of several growth factors on the in vitro growth of murine bone marrow CFU-F. Experimental Hematology 1990; 18(4): 341-347. (PMID: 2323369)

9. Tuan RS, Boland G, Tuli R. Adult mesenchymal stem cells and cellbased tissue engineering. Arthritis Research \& Therapy 2003; 5(1): 3245. (doi: 10.1186/ar614)

10. Sarugaser R, Lickorish D, Baksh D, Hosseini MM, Davies JE. Human umbilical cord perivascular (HUCPV) cells: a source of mesenchymal progenitors. Stem cells (Dayton, Ohio) 2005; 23(2): 220-229. (doi: 10.1634/stemcells.2004-0166)

11. Huss R. Perspectives on the morphology and biology of CD34-negative stem cells. Journal of Hematotherapy \& Stem Cell Research 2000; 9(6): 783-793. (doi: 10.1089/152581600750062228)

12. Hristov M, Erl W, Weber PC. Endothelial progenitor cells: isolation and characterization. Trends Cardiovasc Med 2003; 13(5): 201-206. (PMID: 12837583) (doi: 10.1016/S1050-1738(03)00077-X)

13. Pittenger MF, Mackay AM, Beck SC, Jaiswal RK, Douglas R, Mosca JD, et al. Multilineage potential of adult human mesenchymal stem cells. Science 1999; 284(5411): 143-147. (PMID: 10102814) (doi: 10.1126/science.284.5411.143)

14. Yoo JU, Barthel TS, Nishimura K, Solchaga L, Caplan Al, Goldberg VM, Johnstone $B$. The chondrogenic potential of human bone-marrowderived mesenchymal progenitor cells. J Bone Joint Surg Am 1998; 80(12): 1745-1757. (PMID: 9875932)

15. Jiang $Y$, Vaessen $B$, Lenvik $T$, Blackstad $M$, Reyes $M$, Verfaillie $C M$. Multipotent progenitor cells can be isolated from postnatal murine bone marrow, muscle, and brain. Experimental Hematology 2002; 30(8): 896-904. (PMID: 12160841).

16. Alhadlaq A, Mao JJ. Tissue-engineered neogenesis of human-shaped mandibular condyle from rat mesenchymal stem cells. J Dent Res 2003 . 
82(12): 951-956. (doi: 10.1177/154405910308201203) (PMID: 14630893)

17. Meirelles $L$ da $S$, Nardi NB. Murine marrow-derived mesenchymal stem cell: isolation, in vitro expansion, and characterization. British Journal of Haematology 2003; 123(4): 702-711. (doi: 10.1046/j.13652141.2003.04669.x)

18. Kadiyala S, Young RG, Thiede MA, Bruder SP. Culture expanded canine mesenchymal stem cells possess osteochondrogenic potential in vivo and in vitro. Cell Transplantation 1997; 6(2): 125-134. (PMID: 9142444).

19. Sanchez-Ramos J, Song S, Cardozo-Pelaez F, Hazzi C, Stedeford T, Willing $A$, et al. Adult bone marrow stromal cells differentiate into neural cells in vitro. Experimental Neurology 2000; 164(2): 247-256. (doi: 10.1006/exnr.2000.7389)

20. Xiang $Y$, Zheng Q, Jia B, Huang G, Xu Y, Wang J, Pan Z. Ex vivo expansion and pluripotential differentiation of cryopreserved human bone marrow mesenchymal stem cells. Journal of Zhejiang University. Science. B 2007; 8(2): 136-146. (doi: 10.1631/jzus.2007.B0136).

21. Song $L$, Tuan RS. Transdifferentiation potential of human mesenchymal stem cells derived from bone marrow. FASEB journal 2004; 18(9): 980982. (doi: 10.1096/fj.03-1100fje)

22. Li W, Liu SN, Luo DD, Zhao L, Zeng LL, Zhang SL, Li SL. Differentiation of hepatocytoid cell induced from whole-bone-marrow method isolated rat myeloid mesenchymal stem cells. World J Gastroenterol 2006; 12(30): 4866-4869. (PMID: 16937469) (doi: 10.3748/wjg.v12.i30.4866)

23. Oh SH, Miyazaki $M$, Kouchi $H$, Inoue $Y$, Sakaguchi $M$, Tsuji $T$, et al. Hepatocyte growth factor induces differentiation of adult rat bone marrow cells into a hepatocyte lineage in vitro. Biochemical and Biophysical Research Communications 2000; 279(2): 500-504. (doi: 10.1006/bbrc.2000.3985)

24. Ong SY, Dai H, Leong KW. Inducing hepatic differentiation of human mesenchymal stem cells in pellet culture. Biomaterials 2006a; 27(22): 4087-4097. (doi: 10.1016/j.biomaterials.2006.03.022)

25. Ong SY, Dai H, Leong KW. Hepatic differentiation potential of commercially available human mesenchymal stem cells. Tissue Engineering 2006b; 12(12): 3477-3485. (PMID: 17518684) (doi: 10.1089/ten.2006.12.3477)

26. Lange C, Bruns H, Kluth D, Zander AR, Fiegel HC. Hepatocytic differentiation of mesenchymal stem cells in cocultures with fetal liver cells. World J Gastroenterol 2006; 12(15): 2394-2397. (PMID: 16688831) (doi: 10.3748/wjg.v12.i15.2394)

27. Taléns-Visconti R, Bonora A, Jover R, Mirabet V, Carbonell F, Castell JV, Gómez-Lechón MJ. Hepatogenic differentiation of human mesenchymal stem cells from adipose tissue in comparison with bone marrow mesenchymal stem cells. World J Gastroenterol 2006; 12(36): 5834-5845. (PMID: 17007050) (doi: 10.3748/wjg.v12.i36.5834)

28. Makino S, Fukuda K, Miyoshi S, Konishi F, Kodama H, Pan J, et al. Cardiomyocytes can be generated from marrow stromal cells in vitro. The Journal of Clinical Investigation 1999; 103(5): 697-705. (doi: $10.1172 / \mathrm{JCl} 5298)$

29. Fukuhara S, Tomita S, Yamashiro S, Morisaki T, Yutani C, Kitamura S, Nakatani T. Direct cell-cell interaction of cardiomyocytes is key for bone marrow stromal cells to go into cardiac lineage in vitro. $J$ Thorac Cardiovasc Surg 2003; 125(6): 1470-1480. (PMID: 12830069) (doi: 10.1016/S0022-5223(02)73610-6)

30. Rangappa S, Fen C, Lee EH, Bongso A, Sim EK. Transformation of adult mesenchymal stem cells isolated from the fatty tissue into cardiomyocytes. Ann Thorac Surg 2003; 75(3): 775-779. (PMID: 12645692).

31. Shim WS, Jiang $S$, Wong $P$, Tan J, Chua YL, Tan YS, et al. Ex vivo differentiation of human adult bone marrow stem cells into cardiomyocyte-like cells. Biochemical and Biophysical Research Communications 2004; 324(2): 481-488. (doi: 10.1016/j.bbrc.2004.09.087)

32. Xaymardan M, Tang L, Zagreda L, Pallante B, Zheng J, Chazen JL, et al. Platelet-derived growth factor- $A B$ promotes the generation of adult bone marrow-derived cardiac myocytes. Circulation Research 2004; 94(5): E39-E45. (doi: 10.1161/01.RES.0000122042.51161.B6)

33. Beeres SL, Atsma DE, van der Laarse A, Pijnappels DA, van Tuyn J, Fibbe WE, et al. Human adult bone marrow mesenchymal stem cells repair experimental conduction block in rat cardiomyocyte cultures. Journal of the American College of Cardiology 2005; 46(10): 19431952. (doi: 10.1016/j.jacc.2005.07.055)

34. Nishino $T$, Wang $C$, Mochizuki-Kashio M, Osawa M, Nakauchi H, Iwama A. Ex vivo expansion of human hematopoietic stem cells by garcinol, a potent inhibitor of histone acetyltransferase. PloS One 2011; 6(9): e24298. (doi: 10.1371/journal.pone.0024298)

35. Gallo MP, Ramella R, Alloatti G, Penna C, Pagliaro P, Marcantoni A, et al. Limited plasticity of mesenchymal stem cells cocultured with adult cardiomyocytes. Journal of Cellular Biochemistry 2007; 100(1): 86-99. (doi: 10.1002/jcb.21012)

36. Minguell JJ, Conget $P$, Erices $A$. Biology and clinical utilization of mesenchymal progenitor cells. Braz J Med Biol Res 2011; 33(8): 881887. (PMID: 10920429) (doi: 10.1590/S0100-879X2000000800003)

37. Shiota M, Heike T, Haruyama M, Baba S, Tsuchiya A, Fujino $H$, et al. Isolation and characterization of bone marrow-derived mesenchymal progenitor cells with myogenic and neuronal properties. Experimental Cell Research 2007; 313(5): 1008-1023. (doi: 10.1016/j.yexcr.2006.12.017)

38. Krampera M, Cosmi L, Angeli R, Pasini A, Liotta F, Andreini A, et al. Role for interferon-gamma in the immunomodulatory activity of human bone marrow mesenchymal stem cells. Stem Cells (Dayton, Ohio) 2006; 24(2): 386-398. (doi: 10.1634/stemcells.2005-0008)

39. Le Blanc K, Tammik C, Rosendahl K, Zetterberg E, Ringdén O. HLA expression and immunologic properties of differentiated and undifferentiated mesenchymal stem cells. Experimental Hematology 2003; 31(10): 890-896/ (PMID: 14550804) (doi: 10.1016/S0301472X(03)00110-3)

40. Krampera M, Pasini A, Pizzolo G, Cosmi L, Romagnani S, Annunziato F. Regenerative and immunomodulatory potential of mesenchymal stem cells. Current Opinion in Pharmacology 2006; 6(4): 435-441. (doi: 10.1016/j.coph.2006.02.008)

41. Eliopoulos N, Stagg J, Lejeune L, Pommey S, Galipeau J. Allogeneic marrow stromal cells are immune rejected by $\mathrm{MHC}$ class I- and class IImismatched recipient mice. Blood 2005; 106(13): 4057-4065. (doi: 10.1182/blood-2005-03-1004)

42. Uccelli A, Pistoia V, Moretta L. Mesenchymal stem cells: a new strategy for immunosuppression? Trends in Immunology 2007; 28(5): 219-226. (doi: 10.1016/j.it.2007.03.001)

43. Spaggiari GM, Capobianco A, Becchetti S, Mingari MC, Moretta L. Mesenchymal stem cell-natural killer cell interactions: evidence that activated NK cells are capable of killing MSCs, whereas MSCs can inhibit IL-2-induced NK-cell proliferation. Blood 2006; 107(4): 14841490. (doi: 10.1182/blood-2005-07-2775)

44. Chen X, Xu H, Wan C, McCaigue M, Li G. Bioreactor expansion of human adult bone marrow-derived mesenchymal stem cells. Stem Cells (Dayton, Ohio) 2006; 24(9): 2052-2059. (doi: 10.1634/stemcells.2005-0591)

45. Horwitz EM, Gordon PL, Koo WK, Marx JC, Neel MD, McNall RY, et al Isolated allogeneic bone marrow-derived mesenchymal cells engraft and stimulate growth in children with osteogenesis imperfecta: Implications for cell therapy of bone. Proceedings of the National Academy of Sciences of the United States of America 2002; 99(13): 8932-8937. (doi: 10.1073/pnas.132252399)

46. Koç ON, Gerson SL, Cooper BW, Dyhouse SM, Haynesworth SE, Caplan Al, Lazarus HM. Rapid hematopoietic recovery after coinfusion of autologous-blood stem cells and culture-expanded marrow mesenchymal stem cells in advanced breast cancer patients receiving high-dose chemotherapy. J Clin Oncol 2000; 18(2): 307-316. (PMID: 10637244)

47. Ho A, Hoffman R, Zanjani E. Stem Cell Transplantation: Biology, Processes, Therapy. John Wiley \& Sons, 2006; 268 p. 
48. Zappia E, Casazza S, Pedemonte E, Benvenuto F, Bonanni I, Gerdoni E, et al. Mesenchymal stem cells ameliorate experimental autoimmune encephalomyelitis inducing T-cell anergy. Blood 2005; 106(5): 17551761. (doi: 10.1182/blood-2005-04-1496)

49. Gerdoni E, Gallo B, Casazza S, Musio S, Bonanni I, Pedemonte E, et al. Mesenchymal stem cells effectively modulate pathogenic immune response in experimental autoimmune encephalomyelitis. Annals of Neurology 2007; 61(3): 219-227. (doi: 10.1002/ana.21076)

Authors:

Peyman Ghoraishizadeh - PhD Student and Research assistant, Faculty of Medicine, Laboratory of stem cells and nano-regenerative medicine, Universidad de Los Andes, Santiago, Chile;

Shraddha Raikar - Master and Research assistant, Manipal School Of Regenerative Medicine, Manipal University, Bangalore, India;

Afsoon Ghorishizadeh - Master student, Faculty of basic sciences, Islamic Azad University of Ahar, Ahar, Iran;

Mohadese Hashem Boroojerdi - PhD student, Research assistant, Faculty of Medicine and Health Sciences, Universiti Putra Malaysia, Serdang, Selangor, Malaysia;

Nasibeh Daneshvar - Master, Research assistant , Institute of Bioscience, Universiti Putra Malaysia, Serdang, Selangor, Malaysia. 